\title{
Chapter 7 \\ Do Deep Regional Trade Agreements \\ Enhance International Technology \\ Spillovers? Depth, Breadth, and \\ Heterogeneity
}

\subsection{Introduction}

In Chap. 5, we examine the relationship between bilateral trade patterns and international technology spillovers. In Chap.6, we analyze how horizontal and vertical foreign direct investment (FDI) of multinational enterprises (MNEs) affects technology spillovers between themselves and firms in host countries. Both chapters analyze the issues from theoretical and empirical points of view. Each chapter shows that international trade or FDI is an important channel of international technology spillovers, but the effect on them is heterogeneous, depending on the type of trade patterns or the structure of FDI. In both chapters we measure technology spillovers using patent citation data.

In this chapter, we shed light on the role of deep regional trade agreements (RTAs) in international technology spillovers. As is well known in the field of international economics, trade creation and trade diversion are the most popular effects of signing an RTA (Viner 1950). The dynamic effects of RTAs such as the effects on technology adoption and technology diffusion have been examined by relatively recent studies (e.g., Bustos 2011; Das and Andriamananjara 2006; Ederington and McCalman 2008; Schiff and Wang 2003).

As Jinji et al. (2019a) argue, RTAs may facilitate cross-border technology spillovers both directly and indirectly. The indirect effects of RTAs on cross-border technology spillovers are through international trade in goods and FDI. Since RTAs, particularly deep RTAs with investment provisions, stimulate international trade and FDI, they can facilitate cross-border technology spillovers through an increase in bilateral trade and FDI. A more direct link between RTAs and cross-border technology spillovers may arise from the deep nature of recent RTAs. As examined in Chap. 2, recent RTAs tend to be deeper than old ones. Many RTAs include provisions related to technology, such as trade-related aspects of intellectual property rights (TRIPS), intellectual property right (IPR), innovation policy, and research and development (R\&D). Moreover, some RTAs explicitly include provisions that stimulate 
technology spillovers. For example, the United States-Peru Free Trade Agreement includes a provision on the promotion of innovation and technological development (Article 16.12), which encourages the engagement in collaborative scientific research projects and transfer of technology.

Using patent citations as a proxy for technology spillovers, Jinji et al. (2019a) empirically examine whether RTAs actually enhance international technology spillovers. They use panel data on patent citations at the USPTO for 114 countries/economies for the period 1991-2007. The focus of their study is on whether the depth of RTAs that is measured by the legal enforceability information on the policy areas in the WTO-X group matters for technology spillovers among member countries/economies of RTAs. ${ }^{1}$ They show that the depth of integration actually influences technology spillovers. Interestingly, they find that deeper integration in a broad sense has a greater impact on technology spillovers than do technology-related policy areas. They classify 26 out of 38 policy areas in the WTO-X group into three subsets by utilizing the technique of the factor analysis. Then, they construct a new measure of the nature of deep RTAs by calculating the ratio of the sum of the points of legally enforceable WTO-X policy areas included in each subset that are covered by RTAs to the total points of all legally enforceable WTO-X policy areas covered by the same RTAs. They interpret the first subset as the set of policy areas representing a healthy economic environment in a general sense and the second subset as the set of policy areas representing basic social and economic conditions. The WTO-X policy areas included in these two subsets are not directly related to technology spillovers. On the other hand, the third subset is interpreted as the set of policy areas directly related to competition and technology. Their finding is that the estimated coefficients of the indexes for the first two subsets tend to be larger than those for the third subset.

The analysis in this chapter extends and enriches the study by Jinji et al. (2019a) in several ways. First, as in Jinji et al. (2019a) and Chaps. 5 and 6 of this book, we use patent citations as a proxy of technology spillovers. ${ }^{2}$ We extend the observation period until 2015. Thus, our observation period is 25 years from 1991 to 2015. The eight-year extension of the observation period from Jinji et al. (2019a) is important because more recent RTAs tend to be much deeper. Second, when we estimate the model, we include directional country-pair fixed effects, which are not included in the analysis in Jinji et al. (2019a), as well as time-varying citing and cited countries fixed effects. As we discuss below, the inclusion of country-pair fixed effects is particularly important to address the endogeneity issue (Baier and Bergstrand 2007). Third, we include intra-national citation data in the analysis, which are not included in the estimations of Jinji et al. (2019a). This is essential to measure the effect of RTAs, as argued by Dai et al. (2014). Finally, although Jinji et al. (2019a) restrict the measurement of deep RTAs to the WTO-X policy areas, we include policy areas in

\footnotetext{
${ }^{1}$ See Chap. 2 for the details of the policy areas in WTO-extra (WTO-X) and WTO-plus (WTO+) groups.

${ }^{2}$ This approach was pioneered by Jaffe et al. (1993) and has been employed by a number of studies (e.g., Branstetter 2006; Cappelli and Montobbio 2020; Hall et al. 2001; Haruna et al. 2010; Jaffe and Trajtenberg 1999; Jinji et al. 2013, 2015; Li 2014; MacGarvie 2006; Maurseth and Verspagen 2002; Murata et al. 2014; Peri 2005).
} 
both WTO+ and WTO-X groups and employ the classification of the policy areas in terms of the depth and breadth of RTAs proposed by Limão (2016). ${ }^{3}$

In this chapter, we first estimate the effects of the depth and breadth indexes of RTAs on bilateral patent citations. With regard to the depth of RTAs, we use the indexes in the fields of tariffs, non-tariff barriers (NTBs), the behind-the-border policies (BBPs), and other policies (OPs). On the other hand, as for the breadth of RTAs, we construct indexes for services, technology, investment/capital, labor, and noneconomic policies (NEPs) fields. Throughout this chapter, we employ the Poisson pseudo-maximum likelihood (PPML) estimator with time-varying citing country fixed effects, time-varying cited country fixed effects, and citing-cited-pair fixed effects, which is recommended in the gravity literature (Anderson and van Wincoop 2003; Head and Mayer 2014; Santos Silva and Tenreyro 2006, 2011; Yotov et al. 2016).

We next analyze the heterogeneous effects of individual RTAs. In the trade literature, a number of previous studies find the heterogeneous effects of RTAs on trade in goods by the type of agreements (Roy 2010; Vicard 2009) and by the characteristics of country-pairs and particular countries (Baier et al. 2019; Behar and Cirera-i Crivillé 2013; Cheong et al. 2015; Vicard 2011). Although Jinji et al. (2019a) investigate the heterogeneous effects of RTAs on technology spillovers by the type of agreements (i.e., customs union versus free trade agreement) and by the characteristics of country-pairs (i.e., North and South combinations), the heterogeneous effects of individual RTAs on technology spillovers have not been investigated. As major sources of international technology spillovers, we focus on RTAs signed by the United States and European countries, such as the North American Free Trade Agreement (NAFTA), the European Community (EC)/European Union (EU), RTAs with the United States, and FTAs with the EC/EU.

The main findings of this chapter are as follows. First, we find that the estimated coefficient on the RTA dummy is positive and highly significant, which confirms the finding by Jinji et al. (2019a) and even strengthens their finding by showing that the significantly positive effect of the RTA dummy is kept even if directional countrypair fixed effects are included. Second, we find that the coefficients on the depth indexes other than the OP index are positive and highly significant, suggesting that technology spillovers among signatories of RTAs are stronger as RTAs are deeper. However, when each of the depth indexes is estimated together with the RTA dummy, the coefficient on the depth index becomes insignificant, which suggests that the additional effect of including the depth policy areas may be small or even negligible. A possible reason for the insignificant additional effect of the depth policy areas is that since most of the recent RTAs tend to become deeper and deeper, the estimated average effect of the RTA dummy partly captures the impact of the depth policy areas on technology spillovers. The problem of multicollinearity may affect the result.

Third, the estimated coefficients on the breadth indexes are all positive and statistically significant, suggesting that technology spillovers among members of RTAs become stronger as RTAs cover more policy areas with legal enforceability in each of

\footnotetext{
${ }^{3}$ See Chap. 2 for the details of the depth and breadth of RTAs by Limão (2016).
} 
the breadth fields. However, similar to the depth indexes, when the breadth indexes are estimated with the RTA dummy, all of them lose their significance. Therefore, the additional effects of including legally enforceable provisions in services, technology, investment/capital, labor, or NEP fields on cross-border technology spillovers may be small or insignificant. Since some of the specific provisions in these fields actually strengthen regulations, this result implies that the same level of the index in each breadth field may include both the positive and negative effects on technology spillovers.

Finally, with regard to the heterogeneous effects of the RTAs signed by the United States and the EU, we find that the impact of NAFTA on bilateral technology spillovers is particularly strong. By contrast, the impacts of the EU and EU enlargement on technology spillovers are weak or not positive. On the other hand, both the RTAs with the United States and the FTAs with the EU enhance technology spillovers. Thus, the results suggest that signing RTAs with technologically advanced countries, such as the United States and major European countries, is effective in stimulating cross-border technology spillovers.

The remainder of the chapter is organized as follows. In Sect.7.2, we explain the empirical framework. In Sect.7.3, we describe the data employed in our empirical analysis. In Sect.7.4, we present our empirical results. Section 7.5 concludes the chapter.

\subsection{Empirical Framework}

In this section, we explain our empirical framework to examine the effects of deep RTAs on international technology spillovers.

\subsubsection{The Depth and Breadth Indexes}

We first explain how we measure the contents of deep RTAs. As explained in Chap. 2, Horn et al. (2010) identify 52 policy areas covered by RTAs and classify them into two groups: WTO-plus (WTO+) and WTO-extra (WTO-X) (See Table 2.1 in Chap. 2 for the details of the WTO+ and WTO-X policy areas). Then, Limão (2016) proposes recategorizing the WTO+ and WTO-X policy areas from the viewpoints of the depth and breadth of RTAs. The depth of RTAs is measured by four fields: (a) import tariffs, (b) NTBs, (c) BBPs, and (d) OPs. On the other hand, the breadth of RTAs is measured by five fields: (a) services, (b) technology, (c) investment/capital, (d) labor, and (e) NEPs. Which policy areas are classified into each field of the depth and breadth measures is shown in Table 2.2 in Chap. 2 .

For each field of the depth measure, we construct the following index: 


$$
R T A \_D e p t h \_d \_i n d e x_{i j t}=\frac{\sum_{p \in \Theta^{d}} M a x_{-} L E_{i j t}^{p}}{2 K^{d}},
$$

where Depth_d $\in\{$ Tariff, NTB, BBP,OP\} indicates the fields of the depth measure, $\Theta^{d}$ is the set of policy areas that consist of the field $d \in\{$ Tariff, NTB, $B B P, O P\}, M a x \_L E_{i j t}^{p} \in\{0,1,2\}$ is the maximum point of the LE index of policy area $p$ in all RTAs of which countries $i$ and $j$ are members in year $t$ if they sign any common RTAs, and $K^{d}$ is the number of policy areas in field $d$. Note that $2 K^{d}$ in the denominator of Eq. (7.1) is the total points of the LE index of policy areas in field $d$ if all LE indexes are equal to two in field $d$. Thus, $R T A \_D e p t h \_d \_i n d e x_{i j t}$ takes the value between zero and one.

Similar to the depth measure, we construct the following index for each field of the breadth measure:

$$
R T A \_B r e a d t h \_c \_i n d e x_{i j t}=\frac{\sum_{p \in \Theta^{c}} M a x \_L E_{i j t}^{p}}{2 K^{c}},
$$

where Breadth_c $\in\{G A T S$, Tech, Cap, Lab, non-EP $\}$ indicates the fields of the breadth measure, $\Theta^{c}$ is the set of policy areas that consist of the field $c \in$ $\{G A T S, T e c h, C a p, L a b$, non-EP $\}, M a x_{-} L E_{i j t}^{p} \in\{0,1,2\}$ is the maximum point of the LE index of policy area $p$ in all RTAs of which countries $i$ and $j$ are members in year $t$ if they sign any common RTAs, and $K^{c}$ is the number of policy areas in field $c$.

\subsubsection{RTA Dummies}

Let us next explain our RTA dummies. In addition to the usual RTA dummy, we use various dummies to capture the heterogeneous effects of individual RTAs by decomposing the RTA dummy.

First of all, RT A dummy $y_{i j t}$ is a dummy variable that takes the value of unity if countries $i$ and $j$ both belong to the same RTA in $t$ and zero otherwise. Next, we decompose the RT A dummy $y_{i j t}$ in two ways. The first decomposition is to take into account the NAFTA and the EC/EU. That is, we set $N A F T A_{i j t}$, which is a dummy variable that takes the value of unity if countries $i$ and $j$ both belong to the NAFTA in $t$ and zero otherwise. Similarly, $E U_{i j t}$ is a dummy variable that takes the value of unity if they both belong to the EC/EU in $t$ and zero otherwise. Furthermore, we set $O$ ther_RT $A_{i j t}$, which is a dummy variable that takes the value of unity if they both belong to the same RTA other than the NAFTA and the EC/EU in $t$ and zero otherwise.

Next, our second decomposition of the RTA dummy is to take into account RTAs signed by the United States other than the NAFTA and EU enlargement from 1995. We construct $R T A \_w i t h \_U S_{i j t}$, which is a dummy variable that takes the value of unity if either of countries $i$ and $j$ is the United States and the two countries belong 
to the same RTA other than the NAFTA in $t$ and zero otherwise. $E U_{-} E n l a r g e_{i j t}$ is a dummy variable that takes the value of unity if at least one of the two countries $(i$ and $j$ ) becomes a member of the EU in or after 1995 and both they are the members of the EU in year $t$ and zero otherwise. Moreover, FT A_with_EU $U_{i j t}$ is a dummy variable that takes the value of unity if either of countries $i$ and $j$ is a member of the EC/EU in $t$ and the other country is not a member of the EC/EU in $t$ but countries $i$ and $j$ belong to the same FTA in $t$ and zero otherwise. Finally, non_US_EU_RT $A_{i j t}$ is a dummy variable that takes the value of unity if they belong to the same RTA in $t$ and NAFT $A_{i j t}=E U_{i j t}=R T A \_w i t h \_U S_{i j t}=$ $E U \_E n l a r g e_{i j t}=F T A \_w i t h \_E U_{i j t}=0$ holds for them in $t$ and zero otherwise. ${ }^{4}$

In addition, we use the GATT/WTO dummy. That is, WTO dumm $y_{i j t}$ is a dummy variable that takes the value of unity if both of countries $i$ and $j$ are GATT/WTO members in $t$ and zero otherwise.

\subsubsection{Empirical Model and Strategy}

We next specify a model of knowledge flows between countries and discuss our empirical strategy to estimate the model.

We first measure technology spillovers from country $j$ to country $i$ at time $t$ by extending the framework proposed by Jaffe et al. (1993), Jaffe and Trajtenberg (1999), and Peri (2005). Let $\Phi_{i j t}$ be the actual flow of knowledge from country $j$ to country $i$ at time $t$ in terms of the actual effects on the research output in country $i$. Then, we assume that $\Phi_{i j t}$ depends on both the knowledge stock in country $j$ at $t$, $K_{j t}$, and the research ability of firms in country $i$ at $t, Q_{i t}$, as follows:

$$
\Phi_{i j t}=\left(Q_{i t}\right)^{\alpha_{1}}\left(\tilde{\phi}_{i j t} K_{j t}\right)^{\alpha_{2}}
$$

where $\tilde{\phi}_{i j t} \in[0,1]$ is the degree of accessibility for firms in country $i$ to the knowledge stock in country $j$ at $t$. Thus, $\left(\tilde{\phi}_{i j t} K_{j t}\right)$ is the effective unit of country $j$ 's knowledge stock from the perspective of firms in country $i$. Parameters $\alpha_{1}$ and $\alpha_{2}$ are both positive. For notational simplicity, we relabel $\tilde{\phi}_{i j t}$ as $\phi_{i j t} \equiv\left(\tilde{\phi}_{i j t}\right)^{\alpha_{2}}$.

The degree of accessibility for firms in country $i$ to the knowledge stock in country $j$ at $t, \phi_{i j t}$, depends on the economic distance between countries $i$ and $j$, which is affected by not only bilateral geographical distance but also other potential resistance factors (Peri 2005, p. 310). The resistance factors include both time-invariant and time-varying country-pair specific characteristics. The time-invariant country-pair specific characteristics include bilateral geographical distance, the use of a common

\footnotetext{
${ }^{4}$ Note that in the second decomposition we do not set a dummy variable for the country-pairs of which both countries were the members of the EC/EU before 1995. However, with the use of country-pair fixed effects in our estimations, this omission of the dummy variable for the old members of the EC/EU does not affect the estimations, because this dummy always takes the value of unity during our observation period.
} 
language, and so on. On the other hand, the time-varying country-pair specific characteristics, which affect the economic distance between two countries, are typically represented by the membership of the same RTA and that of GATT/WTO.

Let $\boldsymbol{x}_{i j t}$ be a set of bilateral country characteristics. Then, we have

$$
\begin{aligned}
\phi_{i j t}= & \phi\left(\boldsymbol{x}_{i j t}\right) \\
= & e^{\xi_{i j}} e^{\gamma_{1}\left(R T A \text { dummies }_{i j t}\right)} e^{\gamma_{2}(\text { DRTA_index } i j t)} \\
& \times e^{\gamma_{3}\left(\text { WTO dummy } y_{i j t}\right)},
\end{aligned}
$$

where $\xi_{i j}$ denotes the time-invariant country-pair specific characteristics and DRT A_index ${ }_{i j t}$ denotes various indexes of the depth and breadth of RTAs.

Since $\Phi_{i j t}, Q_{i t}$, and $K_{j t}$ in Eq. (7.3) are not directly observable, we need to use some proxies for those variables in our analysis. We use $C_{i j t}$, the number of patent citations made by the patents of country $i$ to those of country $j$ at time $t$, as a proxy for $\Phi_{i j t}$. Moreover, following the gravity literature (Head and Mayer 2014; Yotov et al. 2016), we capture $Q_{i t}$ by the time-varying citing country fixed effects, $\tilde{\mu}_{i t}$, and $K_{j t}$ by the time-varying cited country fixed effects, $\tilde{v}_{j t}$. According to Peri (2005), we assume the following relationship between $C_{i j t}$ and $\Phi_{i j t}$ :

$$
C_{i j t}=\tilde{\lambda}_{i j} \Phi_{i j t} e^{\epsilon_{i j t}}
$$

where $\tilde{\lambda}_{i j}$ denotes the time-invariant individual effect associated with patent citations between the two countries and $e^{\epsilon_{i j t}}$ is an error term with zero-mean distribution.

Substitute Eqs. (7.3) and (7.4), $\tilde{\mu}_{i t}$ and $\tilde{v}_{j t}$ into Eq. (7.5) to obtain

$$
\begin{aligned}
& C_{i j t}=\tilde{\lambda}_{i j}\left(\tilde{\mu}_{i t}\right)^{\alpha_{1}}\left(\tilde{v}_{j t}\right)^{\alpha_{2}} e^{\xi_{i j}} e^{\gamma_{1}\left(R T A \text { dummies }_{i j t}\right)} e^{\gamma_{2}\left(D R T A \_i n d e x_{i j t}\right)}
\end{aligned}
$$

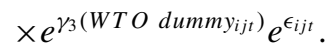

This equation is quite similar to the standard gravity equation that specifies the relationship between the volume of bilateral trade and the market sizes of the two countries with bilateral geographical distance (Anderson and van Wincoop 2003; Head and Mayer 2014; Yotov et al. 2016). By redefining the fixed effects variables, Eq. (7.6) can be rewritten as

$$
\begin{aligned}
& C_{i j t}=\exp \left(\gamma_{1} R T A \text { dummies }_{i j t}+\gamma_{2} \text { DRTA_index }{ }_{i j t}+\gamma_{3} \text { WTO dummy } y_{i j t}\right. \\
& \left.+\zeta_{i j}+\mu_{i t}+v_{j t}+\epsilon_{i j t}\right)
\end{aligned}
$$

Equation (7.7) is our estimation equation for the analysis in Sect. 7.4. In this equation, we use the RTA dummy and the decomposed RTA dummies that we construct in Sect. 7.2.2. We also use the depth and breadth indexes that we construct in Sect. 7.2.1

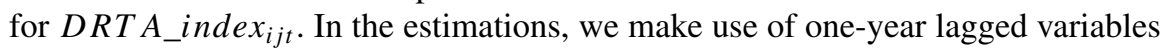
for RT A dummies ijt $_{\text {, DRT A_index }}$ ijt , and WTO dummy $y_{i j t}$. 
In the estimations, we employ the PPML estimator with time-varying citing country fixed effects, time-varying cited country fixed effects, and directional countrypair fixed effects, recommended in the gravity literature (Anderson and van Wincoop 2003; Head and Mayer 2014; Santos Silva and Tenreyro 2006, 2011; Yotov et al. 2016). As is popularly argued in the gravity literature, the use of PPML estimator with time-varying country fixed effects can address the issues of many observations with zero value for the dependent variable and unobservable multilateral resistance terms. Now there is one important issue that we should address the potential endogeneity of RTAs. Possible sources of such endogeneity are the existence of an omitted variable bias and reverse causality (Baier and Bergstrand 2007). Baier and Bergstrand (2007) and Yotov et al. (2016) recommend the use of country-pair fixed effects to take "the unobservable linkages between the endogenous trade policy covariate and the error term in gravity regressions" (Yotov et al. 2016, p.21) into account. We follow their recommendation and include citing-cited-country-pair fixed effects in our estimations to address the endogeneity issue.

\subsection{Description of the Data}

The data on patent citations are taken from the Global 2019 edition of the EPO Worldwide Patent Statistical Database (PATSTAT). We extract the patent statistics of the USPTO from the PATSTAT. ${ }^{5}$ This dataset includes information on the application date, the country name of the assignee, the main US patent class, and citations made and received for each patent. We use patent citation data from 1991 to 2015 for our analysis.

The sample includes all countries and economies that are included in the USPTO data during the observation period. Our sample covers 243 countries and economies, which are listed in Table 7.1. We then construct a panel of 11,667 pairs of the citing and cited countries/economies for 25 years from 1991 to 2015.

Data on RTAs are taken from the database provided by Mario Larch (Egger and Larch 2008), ${ }^{6}$ and data on the content of RTAs are taken from the World Bank's website. $^{7}$

Table 7.2 shows the descriptive statistics of the variables.

\subsection{Empirical Results}

In this section, we report our estimation results.

\footnotetext{
${ }^{5} \mathrm{We}$ also extract the patent statistics of the EPO and use them for a robustness check.

${ }^{6}$ www.ewf.uni-bayreuth.de/en/research/RTA-data/index.html.

${ }^{7}$ This dataset was originally provided by Horn et al. (2010) and extended by Hofmann et al. (2019) (datacatalog.worldbank.org/dataset/content-deep-trade-agreements).
} 
Table 7.1 Sampled countries/economies

\begin{tabular}{|c|c|c|c|c|c|c|c|}
\hline No. & Country/Economy & No. & Country/Economy & No. & Country/Economy & No. & Country/Economy \\
\hline 1 & Afghanistan & 64 & Dominican Rep. & 126 & Liberia & 187 & Saint Kitts \& Nevis \\
\hline 2 & Aland Islands & 65 & Ecuador & 127 & Libya & 188 & Saint Lucia \\
\hline 3 & Albania & 66 & Egypt & 128 & Liechtenstein & \multirow[t]{2}{*}{189} & Saint Pierre and \\
\hline 4 & Algeria & 67 & El Salvador & 129 & Lithuania & & Miquelon \\
\hline 5 & American Samoa & 68 & Equatorial Guinea & 130 & Luxembourg & \multirow[t]{2}{*}{190} & \multirow{2}{*}{$\begin{array}{l}\text { Saint Vincent \& } \\
\text { the Grenadines }\end{array}$} \\
\hline 6 & Andorra & 69 & Eritrea & 131 & Macao & & \\
\hline 7 & Angola & 70 & Estonia & 132 & Madagascar & 191 & Samoa \\
\hline 8 & Anguilla & 71 & Eswatini & 133 & Malawi & 192 & San Marino \\
\hline 9 & Antarctica & 72 & Ethiopia & 134 & Malaysia & 193 & $\begin{array}{l}\text { Sao Tome \& } \\
\text { Principe }\end{array}$ \\
\hline 10 & Antigua and Barbuda & 73 & Falkland Islands & 135 & Maldives & 194 & Saudi Arabia \\
\hline 11 & Argentina & 74 & Faroe Islands & 136 & Mali & 195 & Senegal \\
\hline 12 & Armenia & 75 & Fiji & 137 & Malta & 196 & $\begin{array}{l}\text { Serbia \& } \\
\text { Montenegro }\end{array}$ \\
\hline 13 & Aruba & 76 & Finland & 138 & Marshall Islands & 197 & Seychelles \\
\hline 14 & Australia & 77 & France & 139 & Martinique & 198 & Sierra Leone \\
\hline 15 & Austria & 78 & French Guiana & 140 & Mauritania & 199 & Singapore \\
\hline 16 & Azerbaijan & 79 & French Polynesia & 141 & Mauritius & 200 & Sint Maarten \\
\hline 17 & Bahamas & 80 & French Southern & 142 & Mexico & 201 & Slovakia \\
\hline 18 & Bahrain & & Territories & 143 & Micronesia & 202 & Slovenia \\
\hline 19 & Bangladesh & 81 & Gabon & 144 & Moldova & 203 & Solomon Islands \\
\hline 20 & Barbados & 82 & Gambia & 145 & Monaco & 204 & Somalia \\
\hline 21 & Belarus & 83 & Georgia & 146 & Mongolia & 205 & South Africa \\
\hline 22 & Belgium & 84 & Germany & 147 & Montenegro & 206 & Spain \\
\hline 23 & Belize & 85 & Ghana & 148 & Montserrat & 207 & Sri Lanka \\
\hline 24 & Benin & 86 & Gibraltar & 149 & Morocco & 208 & Sudan (the) \\
\hline 25 & Bermuda & 87 & Greece & 150 & Mozambique & 209 & Suriname \\
\hline 26 & Bhutan & 88 & Greenland & 151 & Myanmar & 210 & Svalbard \& \\
\hline 27 & Bolivia & 89 & Grenada & 152 & Namibia & & Jan Mayen \\
\hline 28 & Bonaire, Sint & 90 & Guadeloupe & 153 & Nauru & 211 & Sweden \\
\hline & Eustatius \& Saba & 91 & Guam & 154 & Nepal & 212 & Switzerland \\
\hline 29 & $\begin{array}{l}\text { Bosnia and } \\
\text { Herzegovina }\end{array}$ & 92 & Guatemala & 155 & Netherlands & 213 & Syrian Arab Rep. \\
\hline 30 & Botswana & 93 & Guernsey & 156 & Netherlands antilles & 214 & Taiwan \\
\hline 31 & Bouvet Island & 94 & Guinea & 157 & New Caledonia & 215 & Tajikistan \\
\hline 32 & Brazil & 95 & Guyana & 158 & New Zealand & 216 & Tanzania \\
\hline 33 & British Indian Ocean & 96 & Haiti & 159 & Nicaragua & 217 & Thailand \\
\hline & Territory & \multirow[t]{2}{*}{97} & \multirow{2}{*}{$\begin{array}{l}\text { Heard Islands \& } \\
\text { McDonald Islands }\end{array}$} & 160 & Niger (the) & 218 & Togo \\
\hline 34 & Brunei Darussalam & & & 161 & Nigeria & 219 & Tokelau \\
\hline 35 & Bulgaria & 98 & Holy See & 162 & Niue & 220 & Tonga \\
\hline 36 & Burkina Faso & 99 & Honduras & 163 & Norfolk Island & 221 & Trinidad \& Tobago \\
\hline 37 & Burundi & 100 & Hong Kong & \multirow[t]{2}{*}{164} & \multirow{2}{*}{$\begin{array}{l}\text { Northern Mariana } \\
\text { Islands }\end{array}$} & 222 & Tunisia \\
\hline 38 & Cabo Verde & 101 & Hungary & & & 223 & Turkey \\
\hline 39 & Cambodia & 102 & Iceland & 165 & Norway & 224 & Turkmenistan \\
\hline 40 & Cameroon & 103 & India & 166 & Oman & 225 & Turks \& Caicos \\
\hline
\end{tabular}


Table 7.1 (continued)

\begin{tabular}{|c|c|c|c|c|c|c|c|}
\hline No. & Country/Economy & No. & Country/Economy & No. & Country/Economy & No. & Country/Economy \\
\hline 41 & Canada & 104 & Indonesia & 167 & Pakistan & & Islands \\
\hline 42 & Cayman Islands & 105 & Iran & 168 & Palau & 226 & Tuvalu \\
\hline \multirow[t]{2}{*}{43} & Central African & 106 & Iraq & 169 & Palestine, State of & 227 & Uganda \\
\hline & Republic & 107 & Ireland & 170 & Panama & 228 & Ukraine \\
\hline 44 & Chad & 108 & Isle of Man & 171 & Papua New Guinea & 229 & UAE \\
\hline 45 & Chile & 109 & Israel & 172 & Paraguay & 230 & United Kingdom \\
\hline 46 & China & 110 & Italy & 173 & Peru & \multirow[t]{2}{*}{231} & US Minor \\
\hline 47 & Christmas Island & 111 & Jamaica & 174 & Philippines & & Outlying Islands \\
\hline 48 & Cocos Islands & 112 & Japan & 175 & Pitcairn & 232 & United States \\
\hline 49 & Colombia & 113 & Jersey & 176 & Poland & 233 & Uruguay \\
\hline 51 & Congo & 114 & Jordan & 177 & Portugal & 234 & Uzbekistan \\
\hline 52 & Congo, Dem. Rep. & 115 & Kazakhstan & 178 & Puerto Rico & 235 & Vanuatu \\
\hline 53 & Cook Islands & 116 & Kenya & 179 & Qatar & 236 & Venezuela \\
\hline 54 & Costa Rica & 117 & Kiribati & \multirow[t]{2}{*}{180} & \multirow{2}{*}{$\begin{array}{l}\text { Rep. of North } \\
\text { Macedonia }\end{array}$} & 237 & Viet Nam \\
\hline 55 & Cote d'Ivoire & \multirow[t]{2}{*}{118} & \multirow[t]{2}{*}{$\begin{array}{l}\text { Korea, Dem. } \\
\text { People's Rep. }\end{array}$} & & & 238 & $\begin{array}{l}\text { Virgin Islands, } \\
\text { British }\end{array}$ \\
\hline 56 & Croatia & & & 181 & Reunion & 239 & Virgin Islands, US \\
\hline 57 & Cuba & 119 & Korea, Rep. of & 182 & Romania & 240 & Wallis and Futuna \\
\hline 58 & Curacao & 120 & Kuwait & 183 & Russian Federation & 241 & Yemen \\
\hline 59 & Cyprus & 121 & Kyrgyzstan & 184 & Rwanda & 242 & Zambia \\
\hline 60 & Czechia & 122 & Laos & 185 & Saint Barthelemy & 243 & Zimbabwe \\
\hline 61 & Denmark & 123 & Latvia & \multirow[t]{3}{*}{186} & \multirow{3}{*}{$\begin{array}{l}\text { Saint Helena, } \\
\text { Ascension \& } \\
\text { Tristan da Cunha }\end{array}$} & & \\
\hline 62 & Djibouti & 124 & Lebanon & & & & \\
\hline 63 & Dominica & 125 & Lesotho & & & & \\
\hline
\end{tabular}

\subsubsection{The Depth of RTAs}

First, we estimate the impact of the depth of RTAs on bilateral technology spillovers. The results obtained are reported in Table 7.3. Column (1) shows that the estimated coefficient on the RTA dummy is positive and highly significant. This result confirms the finding by Jinji et al. (2019a) and strengthens their finding by showing that the significantly positive effect of the RTA dummy remains even when directional country-pair fixed effects are included. Signing an RTA increases bilateral citation of patents by $4.8 \%$ on average. ${ }^{8}$

The effects of the four depth indexes are shown in columns (2)-(5). The coefficients on the first three depth indexes are positive and highly significant. The estimated coefficient on RTA_Tariff_index is 0.042 . Since this index consists of two policy areas with four points in total, an increase in one policy area from zero points to two points (i.e., a change from no legal enforceability to legally enforceable

${ }^{8}\left(e^{0.047}-1\right) \times 100 \approx 4.8$. 
Table 7.2 Descriptive statistics

\begin{tabular}{|c|c|c|c|c|c|}
\hline Variable & No. of Obs & Mean & Std. Dev. & Min & $\operatorname{Max}$ \\
\hline$C_{i j t}$ & 291,675 & 527.023 & 28134.360 & 0 & $4,677,583$ \\
\hline$R T A d u m m y_{i j, t-1}$ & 291,675 & 0.206 & 0.405 & 0 & 1 \\
\hline$R T A \_T a r i f f \_i n d e x_{i j, t-1}$ & 291,675 & 0.121 & 0.325 & 0 & 1 \\
\hline$R T A \_N T B \_i n d e x_{i j, t-1}$ & 291,675 & 0.095 & 0.272 & 0 & 1 \\
\hline$R T A \_B B P \_$index $x_{i j, t-1}$ & 291,675 & 0.073 & 0.220 & 0 & 1 \\
\hline$R T A \_O P \_i n d e x_{i j, t-1}$ & 291,675 & 0.035 & 0.150 & 0 & 1 \\
\hline$R T A \_G A T S \_i n d e x_{i j, t-1}$ & 291,675 & 0.073 & 0.261 & 0 & 1 \\
\hline$R T A \_T e c h \_i n d e x_{i j, t-1}$ & 291,675 & 0.045 & 0.147 & 0 & 0.667 \\
\hline$R T A \_C a p \_i n d e x_{i j, t-1}$ & 291,675 & 0.068 & 0.225 & 0 & 1 \\
\hline$R T A \_L a b \_i n d e x_{i j, t-1}$ & 291,675 & 0.049 & 0.194 & 0 & 1 \\
\hline$R T A \_n o n E P \_i n d e x_{i j, t-1}$ & 291,675 & 0.022 & 0.095 & 0 & 0.556 \\
\hline$W T O$ dumm $y_{i j, t-1}$ & 291,675 & 0.567 & 0.500 & 0 & 1 \\
\hline$N A F T A_{i j, t-1}$ & 291,675 & 0.0004 & 0.021 & 0 & 1 \\
\hline$E U_{i j, t-1}$ & 291,675 & 0.035 & 0.185 & 0 & 1 \\
\hline$R T A \_w i t h \_U S_{i j, t-1}$ & 291,675 & 0.001 & 0.032 & 0 & 1 \\
\hline$E U_{-}$Enlarge $_{i j, t-1}$ & 291,675 & 0.005 & 0.070 & 0 & 1 \\
\hline$F T A \_w i t h \_E U_{i j, t-1}$ & 291,675 & 0.051 & 0.220 & 0 & 1 \\
\hline Other_RT $A_{i j, t-1}$ & 291,675 & 0.172 & 0.378 & 0 & 1 \\
\hline$n o n \_U S \_E U \_R T A_{i j, t-1}$ & 291,675 & 0.151 & 0.358 & 0 & 1 \\
\hline
\end{tabular}

policy area) raises bilateral citation of patents by $2.1 \%$ on average. ${ }^{9}$ Similarly, the estimated coefficients of the $R T A \_N T B \_$index and the $R T A \_B B P \_$index are 0.059 and 0.066 , where $R T A \_N T B \_$index and $R T A \_B B P \_$index consist of five policy areas and six policy areas, respectively. Thus, an increase in one policy area from zero points to two points raises bilateral citation of patents by $1.0 \%$ for the NTB index and $1.4 \%$ for the BBP index, respectively. ${ }^{10}$ Only the estimated coefficient on the $R T A_{-} O P \_$index is insignificant.

Columns (6) and (8) show the results on estimations when the RTA dummy and each of $R T A \_N T B \_i n d e x, R T A \_B B P \_i n d e x$, or $R T A \_O P \_$index are jointly used as explanatory variables. The results may suffer from the problem of multicollinearity as the correlations among the RTA dummy and the depth indexes are high. In column (6), both the RTA dummy and the RTA_NTB_index become insignificant, whereas in columns (7) and (8) the coefficient on the RTA dummy is positive and significant but that on the $R T A \_B B P \_$index or the $R T A \_O P \_$index is insignificant. These results imply that the additional effect of including the depth policy areas in the fields of NTB, BBP, and OP may be small or even insignificant. A possible reason for the insignificant additional effect of the depth policy areas is

\footnotetext{
${ }^{9}\left(e^{0.042}-1\right) \times(1 / 4) \times 2 \times 100 \approx 2.1$.

${ }^{10}\left(e^{0.059}-1\right) \times(1 / 10) \times 2 \times 100 \approx 1.0$ and $\left(e^{0.066}-1\right) \times(1 / 12) \times 2 \times 100 \approx 1.4$.
} 


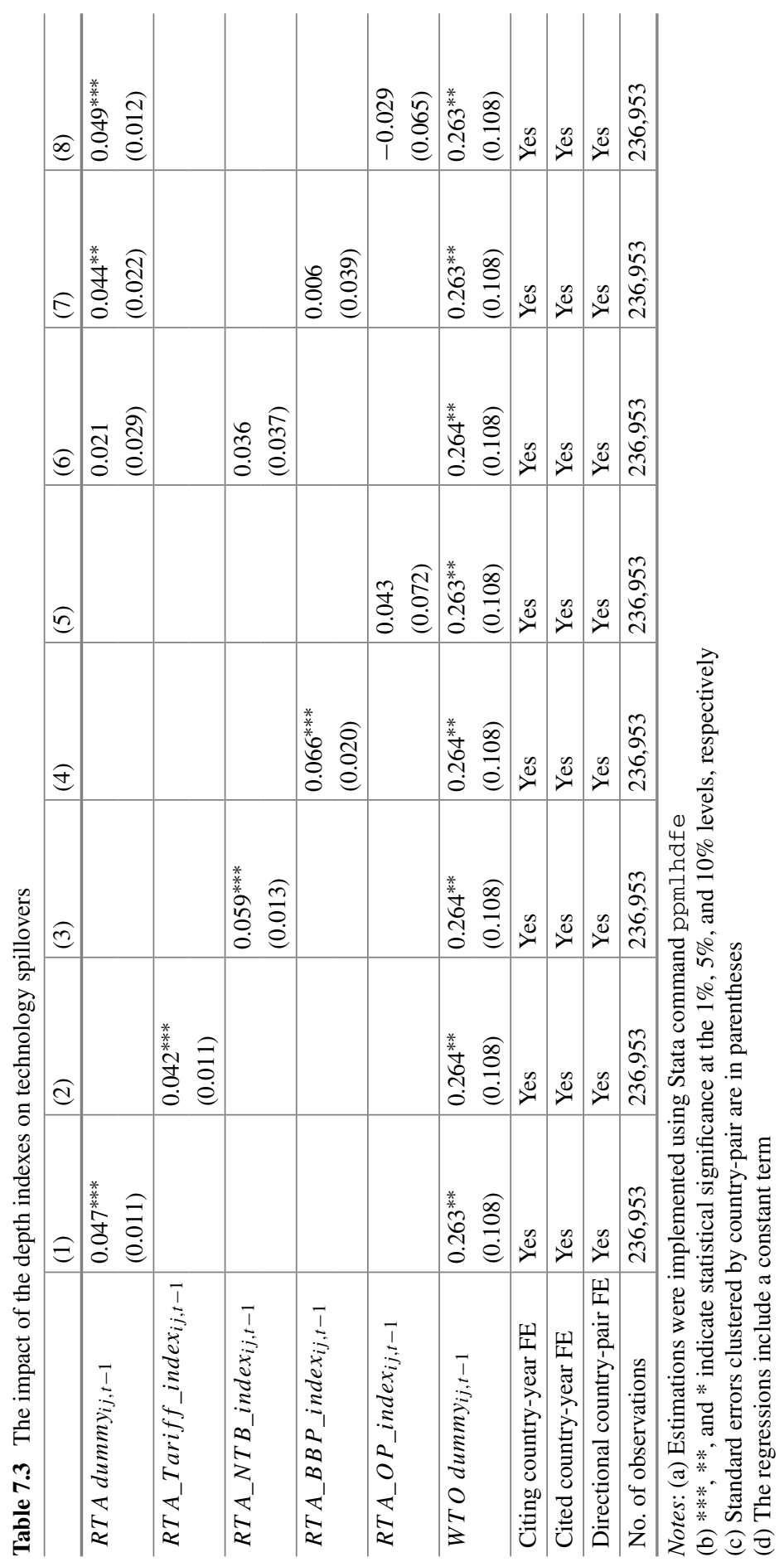


that most of the RTAs that have recently been signed tend to be increasingly deeper. Thus, we can conclude that the estimated average effect of the RTA dummy partly captures the impact of the depth policy areas on technology spillovers.

By contrast, the estimated coefficient on the WTO dummy is positive and highly significant in all columns, and its magnitude is large. If both countries are members of GATT/WTO, then bilateral citations of patents are on average $30.2 \%$ higher than those in other types of country-pairs. ${ }^{11}$

\subsubsection{The Breadth of RTAs}

We next estimate the impact of the breadth of RTAs on bilateral technology spillovers. Estimated results are shown in Table 7.4. Columns (1)-(5) indicate the individual effect of the five breadth indexes: $R T A \_G A T S \_i n d e x, R T A \_T e c h \_i n d e x$, $R T A \_C a p \_i n d e x, R T A \_L a b \_i n d e x$, and $R T A \_n o n E P \_i n d e x$. The estimated coefficients are positive and statistically significant for all of them. For example, the estimated coefficient on the RTA_GATS_index is 0.045 and the GATS field consists of just one policy area, so that an increase in this index from zero points to two points raises cross-border citations of patents by $4.6 \% .^{12}$ Since the coefficient on the RTA_Tech_index is 0.084 and the technology field consists of six policy areas, an increase in one technology-related policy area from zero points to two points raises bilateral citations of patents by $1.5 \% .^{13}$ Similarly, since the coefficient on the RTA_Cap_index is 0.045 and the investment/capital field is comprised of three policy areas, an increase in one investment/capital policy area from zero points to two points raises bilateral citations of patents by $1.5 \% .{ }^{14}$ On the other hand, the impact of the labor-related policy fields becomes much larger. The estimated coefficient on the RT A_Lab_index is 0.133 . The labor field consists of four policy areas, so that a rise in one labor-related policy area from zero point to two points causes bilateral citations of patents by $3.6 \%$ to increase. ${ }^{15}$ The larger impact of the RTAs with legally enforceable labor-related policy areas than those with technology and investment/capital policy areas implies that the movement of workers across countries stimulated by signing RTAs is an important channel of technology spillovers. In column (5), the coefficient on the $R T A \_$non $E P \_$index is 0.189 , where the NEP field consists of nine policy areas, so an increase in one NEP policy area from zero point to two points raises bilateral citations of patents by $2.3 \%{ }^{16}$

Compared with the results above, the results presented in columns (6)-(10) indicate that all of them lose their statistical significance when the breadth indexes are

\footnotetext{
${ }^{11}\left(e^{0.264}-1\right) \times 100 \approx 30.2$.

${ }^{12}\left(e^{0.045}-1\right) \times(1 / 2) \times 2 \times 100 \approx 4.6$.

$13\left(e^{0.084}-1\right) \times(1 / 12) \times 2 \times 100 \approx 1.5$.

$14\left(e^{0.045}-1\right) \times(1 / 6) \times 2 \times 100 \approx 1.5$.

$15\left(e^{0.133}-1\right) \times(1 / 8) \times 2 \times 100 \approx 3.6$.

${ }^{16}\left(e^{0.189}-1\right) \times(1 / 18) \times 2 \times 100 \approx 2.3$.
} 


\begin{tabular}{|c|c|c|c|c|c|c|c|c|c|c|c|c|c|}
\hline & & 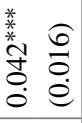 & & & & & 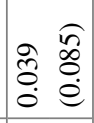 & 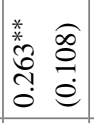 & $\stackrel{\infty}{2}$ & 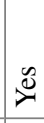 & 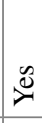 & $\begin{array}{l}\text { బू } \\
\hat{0} \\
\text { ते }\end{array}$ & \\
\hline & & 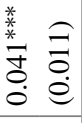 & & & & $\begin{array}{ll}\dot{0} & 0 \\
\dot{0} & 0 \\
0 & 0 \\
\dot{0}\end{array}$ & & 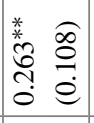 & $\stackrel{\infty}{\approx}$ & $\stackrel{0}{2}$ & $\stackrel{\circlearrowright}{\approx}$ & 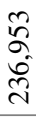 & \\
\hline & & 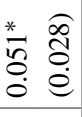 & & & 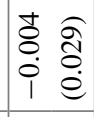 & & & 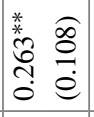 & $\approx$ & $\stackrel{\approx}{2}$ & $\approx$ & $\begin{array}{l}\tilde{2} \\
\hat{0} \\
\text { ते }\end{array}$ & \\
\hline & & 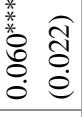 & & 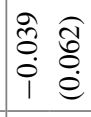 & & & & 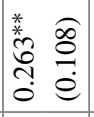 & $\approx$ & $\approx$ & $\approx$ & $\begin{array}{l}\hat{n} \\
\hat{\delta} \\
\text { } \\
\hat{\imath}\end{array}$ & \\
\hline & & 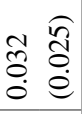 & $\begin{array}{ll}0 & \widehat{\hat{~}} \\
0 & 0 \\
0 & 0 \\
0\end{array}$ & & & & & 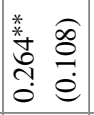 & $\approx$ & $\stackrel{\infty}{\approx}$ & $\stackrel{\infty}{\circlearrowright}$ & $\begin{array}{l}n \\
2 \\
\hat{b} \\
\text { }\end{array}$ & \\
\hline & & & & & & & 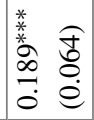 & 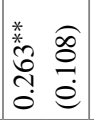 & $\underset{\nu}{\infty}$ & $\stackrel{\infty}{2}$ & 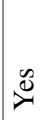 & $\begin{array}{l}\text { ñ } \\
\hat{\delta} \\
\text { ते }\end{array}$ & $\begin{array}{l}\stackrel{0}{0} \\
\mathscr{0} \\
\stackrel{0}{0}\end{array}$ \\
\hline & & & & & & 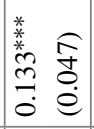 & & 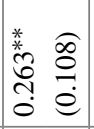 & $\approx$ & $\stackrel{\infty}{2}$ & $\stackrel{\mathbb{\nu}}{ }$ & $\begin{array}{l}n \\
2 \\
0 \\
\tilde{n}\end{array}$ & 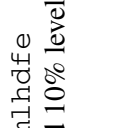 \\
\hline & & & & & 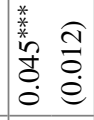 & & & 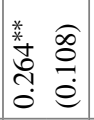 & $\stackrel{0}{*}$ & $\stackrel{\infty}{2}$ & $\stackrel{\circlearrowright}{\approx}$ & 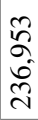 & 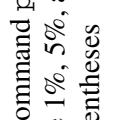 \\
\hline & & & & $\begin{array}{ll}* & 0 \\
* & 0 \\
0 & 0 \\
0 & 0 \\
0 & 0 \\
0 & 0\end{array}$ & & & & 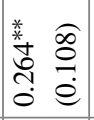 & 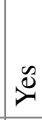 & $\stackrel{\infty}{\infty}$ & $\stackrel{\varnothing}{\infty}$ & $\begin{array}{l}\tilde{n} \\
\hat{\sigma} \\
\hat{\delta} \\
\hat{n}\end{array}$ & 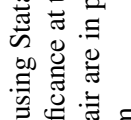 \\
\hline & 2 & & $\begin{array}{ll}* & \\
\stackrel{*}{*} & \Xi \\
\stackrel{0}{*} & \Xi \\
0 & \stackrel{0}{0} \\
\stackrel{0}{0}\end{array}$ & & & & & 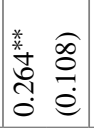 & $\approx$ & $\stackrel{\approx}{2}$ & $\stackrel{0}{\infty}$ & 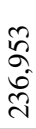 & 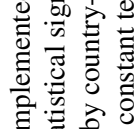 \\
\hline & & 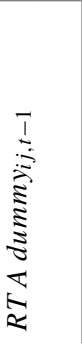 & 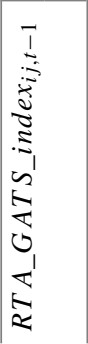 & 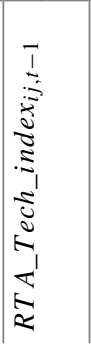 & 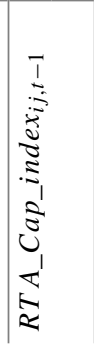 & 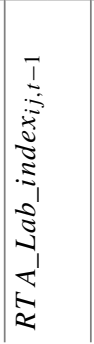 & 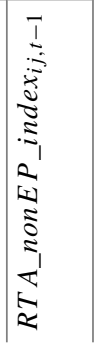 & 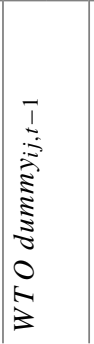 & 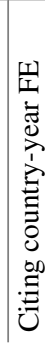 & 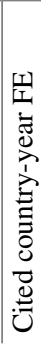 & 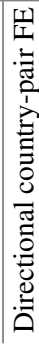 & 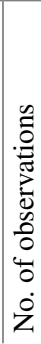 & 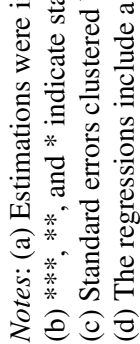 \\
\hline
\end{tabular}


estimated with the $R T A$ dummy. This means that the additional effect of including legally enforceable policy areas in services, technology, investment/capital, labor, or NEP field on bilateral technology spillovers may be negligible. However, it should be noted that the problem of multicollinearity may distort the estimated coefficients of the breadth indexes. Moreover, the inclusion of legally enforceable policy areas in services, technology, investment/capital, labor, or NEP field does not necessarily increase bilateral citations of patents because some of the policy areas in these fields actually strengthen regulations. The same level of the index in each breadth field may include not only the positive effect but also the negative effect on technology spillovers. Consequently, the positive impact of the breadth index may be weakened.

Note that the estimated coefficient on the WTO dummy in Table 7.4 is almost the same as that in Table 7.3.

\subsubsection{Heterogeneous Effects of RTAs by the United States and the $E U$}

Our next focus is on the heterogeneous effects of the RTAs signed by the United States and the EU. Table 7.5 shows the estimated results. Column (1) shows the effects of the NAFTA and the EU. Interestingly, while the estimated coefficient on the NAFTA dummy is positive and highly significant, that of the $E U$ dummy is negative and significant. NAFTA increases bilateral citations of patents among Canada, Mexico, and the United States by $28.5 \%$ on average. ${ }^{17}$ The NAFTA membership is fairly comparable in magnitude to the GATT/WTO membership.

Column (2) reports the effects of RTAs with the United States, EU enlargement, and FTAs with the EU. RTAs with the United States, other than NAFTA, have on average a positive and significant effect on bilateral patent citations. Moreover, although the impact of EU enlargement is insignificant, FTAs with the EU affect positively bilateral patent citations on average. These results suggest that the impact of NAFTA is much larger than that of other RTAs.

\subsubsection{Robustness Check}

The large impact of NAFTA and the small one of the EU on bilateral citations of patents shown in the previous subsection may be due to the use of the USPTO data. In other words, one may suspect that the home bias may cause the heterogeneous effects between NAFTA and the EU.

To check the robustness of the finding in the previous subsection, we employ the EPO data and construct the dataset, so that the same country-pairs are included in both the USPTO and the EPO citations. Then, we estimate the same specifications

${ }^{17}\left(e^{0.251}-1\right) \times 100 \approx 28.5$. 
Table 7.5 Heterogeneous effects of RTAs by the United States and the EU

\begin{tabular}{|c|c|c|}
\hline & $(1)$ & (2) \\
\hline$N A F T A_{i j, t-1}$ & $\begin{array}{l}0.251^{* * *} \\
(0.090)\end{array}$ & $\begin{array}{l}0.259^{* * *} \\
(0.092)\end{array}$ \\
\hline$E U_{i j, t-1}$ & $\begin{array}{l}-0.089^{*} \\
(0.046)\end{array}$ & \\
\hline Other_RT $A_{i j, t-1}$ & $\begin{array}{l}0.040^{* * *} \\
(0.011)\end{array}$ & \\
\hline$R T A \_w i t h \_U S_{i j, t-1}$ & & $\begin{array}{l}0.054^{* * *} \\
(0.011)\end{array}$ \\
\hline$E U \_$Enlarge $e_{i j, t-1}$ & & $\begin{array}{l}0.078 \\
(0.075)\end{array}$ \\
\hline$F T A \_w i t h \_E U_{i j, t-1}$ & & $\begin{array}{l}0.093^{* * *} \\
(0.023)\end{array}$ \\
\hline non_US_EU_RT $A_{i j, t-1}$ & & $\begin{array}{l}-0.009 \\
(0.025)\end{array}$ \\
\hline WTO dummy $y_{i j, t-1}$ & $\begin{array}{l}0.263^{* *} \\
(0.108)\end{array}$ & $\begin{array}{l}0.264^{* *} \\
(0.108)\end{array}$ \\
\hline Citing country-year FE & Yes & Yes \\
\hline Cited country-year FE & Yes & Yes \\
\hline Directional country-pair FE & Yes & Yes \\
\hline No. of observations & 236,953 & 236,953 \\
\hline
\end{tabular}

Notes: (a) Estimations were implemented using Stata command ppml hdfe

(b) $* * *, * *$, and $*$ indicate statistical significance at the $1 \%, 5 \%$, and $10 \%$ levels respectively

(c) Standard errors clustered by country-pair are in parentheses

(d) The regressions include a constant term

with those in Table 7.5 for both the USPTO and the EPO citations. The results are reported in Table 7.6. Columns (1) and (2) show the results of the USPTO citations, and columns (3) and (4) show those of the EPO citations.

Comparing the estimated coefficients on the NAFT A dummy in columns (1)(2) and columns (3)-(4), the coefficient is positive in both columns (3)-(4) and significant in column (4), although the magnitude becomes smaller in columns (3)(4). By contrast, the coefficient on the $E U$ dummy is negative and significant in both columns (1) and (3). The estimated coefficient on the EU enlargement dummy is insignificant in both columns (2) and (4). Moreover, whereas the coefficient on the FT A_with_EU dummy is positive and significant in column (2), it is negative and insignificant in column (4).

We conclude that the findings in Table 7.5 are not due to the home bias and that these findings are robust. 
Table 7.6 Robustness check: USPTO citations versus EPO citations

\begin{tabular}{|c|c|c|c|c|}
\hline & $(1)$ & (2) & (3) & (4) \\
\hline & USPTO & USPTO & EPO & EPO \\
\hline$N A F T A_{i j, t-1}$ & $\begin{array}{l}0.251^{* * *} \\
(0.090)\end{array}$ & $\begin{array}{l}0.259^{* * *} \\
(0.092)\end{array}$ & $\begin{array}{l}0.128 \\
(0.114)\end{array}$ & $\begin{array}{l}0.196^{*} \\
(0.115)\end{array}$ \\
\hline$E U_{i j, t-1}$ & $\begin{array}{l}-0.094^{*} \\
(0.046)\end{array}$ & & $\begin{array}{l}-0.149^{* * *} \\
(0.043)\end{array}$ & \\
\hline Other_RT $A_{i j, t-1}$ & $\begin{array}{l}0.040^{* * *} \\
(0.011)\end{array}$ & & $\begin{array}{l}-0.081^{* * *} \\
(0.026)\end{array}$ & \\
\hline$R T A \_w i t h \_U S_{i j, t-1}$ & & $\begin{array}{l}0.054^{* * *} \\
(0.011)\end{array}$ & & $\begin{array}{l}-0.010 \\
(0.034)\end{array}$ \\
\hline$E U_{-}$Enlarge $e_{i j, t-1}$ & & $\begin{array}{l}0.078 \\
(0.075)\end{array}$ & & $\begin{array}{l}-0.053 \\
(0.061)\end{array}$ \\
\hline FTA_with_EU $U_{i j, t-1}$ & & $\begin{array}{l}0.093^{* * *} \\
(0.024)\end{array}$ & & $\begin{array}{l}-0.039 \\
(0.032)\end{array}$ \\
\hline non_US_EU_RT $A_{i j, t-1}$ & & $\begin{array}{l}-0.010 \\
(0.026)\end{array}$ & & $\begin{array}{l}-0.070^{*} \\
(0.036)\end{array}$ \\
\hline$W T O$ dumm $_{i j, t-1}$ & $\begin{array}{l}0.269^{* *} \\
(0.110)\end{array}$ & $\begin{array}{l}0.270^{* *} \\
(0.110) \\
\end{array}$ & $\begin{array}{l}0.664^{* * *} \\
(0.207)\end{array}$ & $\begin{array}{l}0.665^{\text {*** }} \\
(0.207) \\
\end{array}$ \\
\hline Citing country-year FE & Yes & Yes & Yes & Yes \\
\hline Cited country-year FE & Yes & Yes & Yes & Yes \\
\hline $\begin{array}{l}\text { Directional country-pair } \\
\text { FE }\end{array}$ & Yes & Yes & Yes & Yes \\
\hline No. of observations & 98,546 & 98,546 & 84,578 & 84,578 \\
\hline
\end{tabular}

Notes: (1) Estimations were implemented using Stata command ppmlhdfe

(2) $* * *, * *$, and $*$ indicate statistical significance at the $1 \%, 5 \%$, and $10 \%$ levels, respectively

(3) Standard errors clustered by country-pair are in parentheses

(4) The regressions include a constant term

\subsection{Conclusion}

In this chapter, we investigated the impact of deep RTAs on international technology spillovers, employing patent citations as a proxy of technology spillovers. We extended and enriched the research by Jinji et al. (2019a) in several ways. The focus of our research is on the impacts of the depth and breadth of RTAs and the heterogeneous effects of individual RTAs on international technology spillovers.

Our main findings are as follows. First, we confirmed the finding by Jinji et al. (2019a) that RTAs significantly enhance international technology spillovers measured by bilateral patent citations. We actually strengthened their finding by deriving the one that the significantly positive coefficient on the RTA dummy is kept even when the model is estimated with directional country-pair fixed effects.

Second, we found that deep RTAs with higher coverage of policy areas in the depth fields such as tariffs, NTBs, and BBPs, and those with higher coverage of 
policy areas in the breadth fields such as services, technology, investment/capital, labor, and NEPs at the legally enforceable level have positive effects on international technology spillovers. The additional effects of including the depth or breadth policy areas may be small or even negligible. This may be because the estimated average effect of the RTA dummy partly captures the impact of the depth policy areas on technology spillovers as recent RTAs tend to be increasingly deeper. Moreover, with regard to the breadth fields, the same level of the breadth index may include both the positive and negative effects on technology spillovers, as some policy areas actually strengthen rather than relax regulations. Finally, we found that the NAFTA has a strongly positive impact on international spillovers, whereas the impacts of the EU and EU enlargement on technology spillovers are weak or not positive. However, the RTAs with the United States and the FTAs with the EU both positively affect technology spillovers.

Our empirical results imply that signing deep RTAs with higher coverage of the depth or breadth policy areas is quite effective to enhance bilateral technology spillovers. In addition, signing RTAs with technologically advanced countries, such as the United States and major European countries, is also effective in stimulating cross-border technology spillovers.

Open Access This chapter is licensed under the terms of the Creative Commons Attribution 4.0 International License (http://creativecommons.org/licenses/by/4.0/), which permits use, sharing, adaptation, distribution and reproduction in any medium or format, as long as you give appropriate credit to the original author(s) and the source, provide a link to the Creative Commons license and indicate if changes were made.

The images or other third party material in this chapter are included in the chapter's Creative Commons license, unless indicated otherwise in a credit line to the material. If material is not included in the chapter's Creative Commons license and your intended use is not permitted by statutory regulation or exceeds the permitted use, you will need to obtain permission directly from the copyright holder. 